\title{
Terapia Comunitária e sofrimento psíquico no sistema familiar: um enfoque baseado no novo paradigma da ciência
}

\author{
Community Therapy and psychic distress in the family system: \\ an approach based on the new paradigm of science
}

\author{
Mariana Albernaz Pinheiro de Carvalho (https://orcid.org/0000-0002-2911-324X) ${ }^{1}$ \\ Maria Djair Dias (https://orcid.org/0000-0001-7039-4154) ${ }^{2}$ \\ Sandra Aparecida de Almeida (https://orcid.org/0000-0002-2183-6769) ${ }^{2}$ \\ Rosa Lúcia Rocha Ribeiro (https://orcid.org/0000-0002-7671-702X) ${ }^{3}$ \\ Priscilla Maria de Castro Silva (https://orcid.org/0000-0002-0344-8367) ${ }^{1}$ \\ Maria de Oliveira Ferreira Filha (https://orcid.org/0000-0002-2400-6760) ${ }^{2}$
}

${ }^{1}$ Universidade Federal de Campina Grande. Sítio Olho d'Água da Bica s/n, Centro. 58175-000 Cuité PB Brasil.mary_albernaz@ hotmail.com

${ }^{2}$ Universidade Federal da Paraíba. João Pessoa PB Brasil.

${ }^{3}$ Universidade Federal de Mato Grosso. Cuiabá MT Brasil.

\begin{abstract}
The scope of this study was to analyze the behavior patterns adopted by family members dealing with individuals in psychological distress within the scope of the relationships established in the family system, after participating in Community Therapy sessions. It was based on research with a qualitative approach using the research-action-intervention method. The intervention used centered around twelve Community Therapy sessions. Ten family members of people in psychological distress monitored by a Psychosocial Care Center took part in the study. Field notebook records, videos obtained with the tapes of the Community Therapy sessions, the interview material and Community Therapy itself were used as the empirical material production technique. The study revealed that the family members' understanding of psychological distress could be transformed as they attributed new meanings and performed fundamental actions to balanced living in the family. Community Therapy was seen as a practice that facilitated changes in the lives of its participants, as it contributed to generate social and individual interactions that stimulated family members to rethink concepts and to create spaces of coexistence and human and respectful care that permeated the family unit.
\end{abstract}

Key words Family, Mental health, Social Support, Community Health Services, Mental Health Services
Resumo O presente estudo buscou analisar os comportamentos adotados por familiares que lidam com entes em sofrimento psíquico, no âmbito das relações estabelecidas no sistema familiar, depois de participarem de rodas de Terapia Comunitária. Pesquisa de abordagem qualitativa que utilizou o método da pesquisa-ação-intervenção. A intervenção utilizada foram doze rodas de Terapia Comunitária. Fizeram parte do estudo dez familiares de pessoas em sofrimento psíquico acompanhadas em um Centro de Atenção Psicossocial. Como técnicas de produção do material empírico foram utilizados os registros do caderno de campo, os vídeos obtidos com a gravação das rodas de Terapia Comunitária, o material das entrevistas e a própria Terapia Comunitária. O estudo revelou que a compreensão dos familiares acerca do sofrimento psíquico pôde ser transformada na medida que atribuiam novos significados e realizavam ações fundamentais ao convívio equilibrado na família. A Terapia Comunitária pôde ser elucidada como uma prática que facilitou mudanças na vida de seus participantes, pois contribuiu para gerar interações sociais e individuais que estimularam os familiares a repensarem conceitos e a criarem espaços de convivência e cuidado humanos e respeitosos que se difundiram para o sistema familiar.

Palavras-chave Família, Saúde Mental, Apoio Social, Serviços de Saúde Comunitária, Serviços de Saúde Mental 


\section{Introdução}

A Ciência vem sofrendo transformações e evoluindo ao longo dos tempos, a partir de paradigmas distintos, porém complementares, que proporcionaram uma verdadeira revolução na história do pensamento científico. Nessa lógica, a ciência tradicional e suas conjecturas mergulharam em uma profunda e emergente crise, disparada, sobretudo, pelos postulados dos estudiosos Max Plank, Albert Einstein (a partir do princípio da relatividade), Niels Bohr, Boltzman, Heisenberg (princípio da incerteza), dentre outros cientistas. A partir de tais descobertas, as leis da Física adquiriram um perfil probabilístico, e a tese de determinismo mecanicista e o salvacionismo limitante da ciência foram refutados, uma vez que a completude não mais se limitava à integração das partes, e isso resultou na consciência de uma complexidade que distinguia o sujeito do objeto, criando novas possibilidades para se pensar e fazer ciência ${ }^{1-4}$.

Assim, em meados do século XX, a ciência moderna e clássica defrontou-se com uma concepção sistêmica de mundo e rompeu com sua epistemologia tradicional e seus pressupostos por meio de uma crise paradigmática, com críticas que envolviam seus conceitos, sua matéria e sua natureza, o que culminou em profundas reflexões epistemológicas no campo do conhecimento científico ${ }^{1}$.

A partir de então, surgiu a ideia de pensamento sistêmico como uma visão de mundo em que se priorizavam a natureza e os atributos das relações, visto que o método analítico passava a ser inadequado quando se tratava de discussões e análises envolvendo as ciências humanas, devido à sua subjetividade e complexidade ${ }^{2}$.

A ideia de pensamento sistêmico enquanto o "novo paradigma da ciência" ou pensamento novo-paradigmático, refere-se $\mathrm{s}^{5}$ uma compreensão de mundo baseada em sistemas. Tais sistemas representam os modos através dos quais se estruturam as relações e os elementos que as compõem.

Tal transição paradigmática é notoriamente encontrada no campo da saúde, onde as práticas institucionais e profissionais, as políticas públicas e a própria formação acadêmico-científica ainda se estruturam em uma lógica curativista, médico-hegemônica e fragmentadora, que se harmonizam com o paradigma da ciência tradicional.

Assim, quando se fala de sistema, a família é um dos principais exemplos fundamentados em redes de convivência e de conversações, dotados de características particulares, além de diferentes arranjos de conduta originados de estados emocionais, comportamentais, situacionais e contextuais. Ao se pensar em família na perspectiva sistêmica, identifica-se que seu conceito vem se modificando e se tornando cada vez mais amplo, com o estabelecimento de novos padrões culturais, valores, costumes, determinantes sociais e concepções em constantes redefinições ${ }^{1,6}$.

Quando se trata da família que convive com a realidade do sofrimento psíquico, a mesma passa a ser um importante alvo de atenção, uma vez que necessita acolher e conviver com o ente "adoecido", além de desenvolver recursos adaptativos de modo a manter o equilíbrio de sua estrutura enquanto um sistema complexo, instável e que tem sua dinâmica transformada. No entanto, para que isso aconteça, os familiares precisam contar com uma rede de apoio profissional e social para auxiliá-los nesse processo.

Nesse contexto, a família se sente muitas vezes desassistida e encontra inúmeras barreiras não apenas de acesso aos dispositivos de saúde mental, mas também de cuidados voltados ao atendimento de suas dificuldades e inseguranças ${ }^{7-9}$.

Nesse sentido, o amparo às famílias deve assegurar o suporte necessário para o enfrentamento dos desafios diários, para evitar que os problemas experimentados se transformem em conflitos arbitrados pelo estorvo de relacionamento com o sujeito em adoecimento mental, capaz de romper e de fragilizar as relações.

Partindo-se dessas colocações, sabe-se que o contexto social, histórico e cultural sofre transformações e modifica suas concepções a respeito da "loucura", do mesmo modo que a família também evolui a partir desses ${ }^{10}$ conceitos. Então, modifica-se a maneira de se compreender o sofrimento psíquico, uma vez que o esteio familiar tem sido considerado um dos grandes fatores implicados na origem, na culpabilidade e no cuidado do sujeito em adoecimento mental ${ }^{11}$.

Destarte, em razão do número cada vez maior de serviços que substituem os hospitais psiquiátricos e do advento de políticas de atenção em saúde mental na perspectiva da atenção primária e secundária, as abordagens grupais representam um dos grandes eixos terapêuticos a serem aplicados no sistema familiar.

Portanto, para que essas abordagens se materializem, é necessário fomentar práticas sociais que incentivem o pensar/criar/fazer. Dentre essas práticas, destaca-se a Terapia Comunitária Integrativa (TCI) como uma intervenção psicossocial avançada, realizada por pessoas devidamente capacitadas, denominadas terapeutas comunitários. 
O terapeuta tenta articular a dimensão biológica, social e política dos problemas apresentados pelos participantes das rodas de TCI e posiciona-se como um sujeito novo-paradigmático.

A TCI foi criada no ano de 1987 pelo médico, professor e antropólogo Adalberto de Paula Barreto, em Fortaleza-CE. Acredita-se que mais de 38.000 terapeutas comunitários já foram capacitados pelos diversos polos formadores. Dentro desse quantitativo, mais de 3.000 são representados por profissionais de saúde, líderes influentes na comunidade e pessoas formadas por meio de parcerias governamentais. Cabe destacar ainda o crescimento e a expansão dessa metodologia de cuidado para vários países da Europa, da África e da América do Sul ${ }^{12}$.

Nesse contexto, destaca-se a Política Nacional de Práticas Integrativas e Complementares em Saúde (PNPIC), que incorporou a TCI em seu escopo no ano de 2008, com o objetivo de formar novos terapeutas comunitários para fortalecer as estratégias complementares no âmbito da Atenção Básica ${ }^{13}$.

Medida essencial para a expansão e fortalecimento da TCI foi a realização da IV Conferência Nacional de Saúde Mental, ocorrida em Brasília no ano de 2010. Nesse evento, foi aprovado um projeto com vistas a assegurar a continuidade da implantação, da expansão e do fortalecimento da TCI como uma estratégia integrativa e intersetorial de promoção e cuidado em saúde mental recomendada pelo Ministério da Saúde, que por meio da Portaria no 145/2017, incluiu, no leque da PNPIC, a TCI e outras práticas que já desenvolvidas, mas que foram destacadas para facilitar o conhecimento e ampliar o escopo de sua disseminação ${ }^{14}$.

Além da TCI, foram incluídos os seguintes procedimentos: auriculoterapia, meditação, musicoterapia, massoterapia, dança circular/biodança, yoga, oficina de massagem/automassagem e crenoterapia. Atualmente, a PNPIC apresenta, em seu rol, um total de 19 práticas ${ }^{14}$.

A TCI, ao se mostrar útil como uma prática efetiva para uma heterogeneidade de públicos, estimula a fala porquanto propõe que o sujeito se desprenda de inquietações e de conflitos, podendo ser utilizada como uma estratégia facilitadora de reflexões individuais e coletivas ${ }^{15-19}$, geradoras de transformações sistêmicas capazes de promover mais apoio familiar e a inclusão do indivíduo em adoecimento mental na família e na comunidade.

Assim, o presente estudo buscou analisar os comportamentos adotados por familiares que lidam com entes em sofrimento psíquico, no âmbito das relações estabelecidas no sistema familiar, depois de participarem de rodas de Terapia Comunitária.

\section{Métodos}

Utilizou-se o método da pesquisa-ação/intervenção como uma propositura aliada ao método qualitativo, que proporciona uma relação comunicativa e dialógica entre o sujeito pesquisador e o pesquisado ${ }^{20,21}$. No que tange aos procedimentos adotados, trata-se de um estudo intervencional, na medida em que avaliou a aplicação de uma intervenção em que a pesquisadora - que também é terapeuta comunitária - conduziu uma abordagem representada pelas rodas de TCI realizadas com familiares de indivíduos em sofrimento psíquico ${ }^{22}$.

A TCI (ação/intervenção deste estudo) por ser uma tecnologia de prevenção do adoecimento e de promoção da saúde reconhecida pelo Ministério da Saúde, estimula o diálogo dos participantes a partir de suas experiências cotidianas, representando uma possibilidade de intervenção que provoca um movimento de autoconhecimento em seus participantes que os conduz a processos de subjetivação e encontro de sentidos nas situações vivenciadas ${ }^{23}$.

A pesquisa foi realizada em um Centro de Atenção Psicossocial III de João Pessoa-PB. Foram realizadas 12 rodas de TCI durante o período de agosto a novembro de 2017. Participaram do estudo familiares de usuários do CAPS que se enquadraram nos seguintes critérios de inclusão: conviver diretamente com o ente que é usuário do CAPS; mostrar-se sensível à realidade do parente em sofrimento psíquico e demonstrar interesse em participar das rodas de TCI e participar de no mínimo seis rodas de TCI. Ao final, dez familiares compuseram a pesquisa.

A pesquisa utilizou como técnicas de produção do material empírico os registros e impressões do caderno de campo, os vídeos obtidos com a gravação das rodas de TCI, o material apreendido em entrevistas semiestruturadas, além da própria TCI, enquanto técnica que estimulava o suscitar de situações-problemas, estratégias de enfrentamento e sentimentos. A TCI foi desenvolvida conforme sequência de passos ${ }^{24}$ : Acolhimento, Escolha do tema, Contextualização, Problematização e Conclusão/Encerramento.

Para auxiliar a análise das rodas de TCI e as entrevistas semiestruturadas utilizou-se a 
análise de conteúdo temática ${ }^{25}$, facilitada pelo Software Interface de R pour les Analyses Multidimensionnelles de Textes et de Questionnaires (IRAMUTEQ), versão 0.7 alpha 2. Os temas que conduziram as discussões das categorias foram orientados por vocábulos agrupados em três classes evidenciadas a partir do processamento do corpus textual na modalidade de Classificação Hierárquica Descendente (CHD), com seu respectivo dendrograma.

A Figura 1 representa o dendrograma com a distribuição lexical e as relações interclasses com base nas palavras pronunciadas pelos participantes. As categorias derivadas do processamento feito pelo IRAMUTEQ foram: O desafio familiar no convívio com o sofrimento psíquico (Classe 1 - 34,7\% dos segmentos de texto); O diálogo da compreensão e o respeito à alteridade (Classe 2 $26,7 \%$ dos segmentos de texto) e Mudanças nas relações que constituem a posição do sujeito no sistema familiar (Classe $3-38,6 \%$ dos segmentos de texto).

O estudo obedeceu à Resolução no 466/2012 do Conselho Nacional de Saúde ${ }^{26}$. Os participantes foram identificados pela letra "F" seguido do número que expressou a ordem sequencial de realização das entrevistas. A pesquisa foi realizada com a aprovação do Comitê de Ética em Pesquisa, depois de emitido o Certificado de Apresentação para Apreciação Ética (CAAE).

\section{Resultados e discussão}

Dos dez familiares participantes, predominaram cuidadores do sexo feminino (90\%), com uma média de 57,1 anos de idade, a maioria casada (80\%) e com uma média de quatro filhos. A ocupação predominante foi do lar (60\%), e o grau de parentesco foi de mãe (70\%). No que se refere à participação no número de rodas de terapia, a média foi de oito.

\section{O desafio familiar no convívio com o sofrimento psíquico}

Com base no material textual obtido a partir das transcrições das rodas, as situações-problemas mais mencionadas pelos familiares foram: estresse; solidão por não ter com quem dividir as responsabilidades; decepção e desgosto por causa do desamparo familiar; sobrecarga, por não ter com quem partilhar os cuidados e desrespeito social gerado pelo preconceito com o sofrimento psíquico:

Fico muito estressada com a situação do meu filho, então acabo estressando minha filha, meu outro filho e meu marido (F8).

As mudanças de comportamento do indivíduo em sofrimento psíquico podem causar elevados níveis de estresse entre os familiares cuidadores. Ao vivenciar o estresse e a carga de tarefas e de responsabilidades, o cuidador pode vivenciar um desequilíbrio no seio familiar que influencia a qualidade de vida e a habilidade de aceitar a problemática. Então, compreender o estresse é

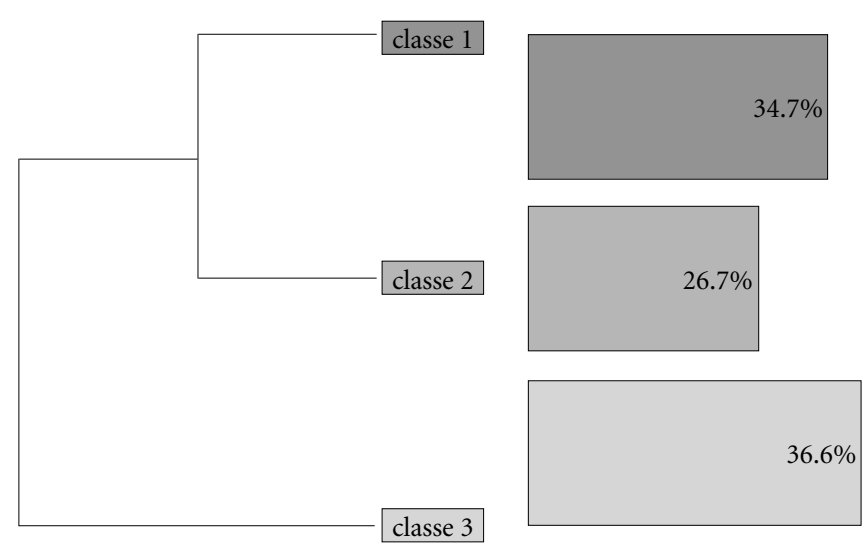

Figura 1. Dendrograma representativo das partições em classes e percentagem das palavras. 
fundamental ao sujeito, a fim de que ele se mobilize para enfrentar, buscar ajuda e suportar os dissabores que $o$ afligem ${ }^{27}$ :

Me sinto muito sozinha. Já pensei até em tirar minha vida, mas não posso abandonar minha filha. Ela só tem a mim (F1).

A indiferença e o abandono por parte da família, além de agravar a condição de sobrecarga do familiar cuidador, desestabilizam-no psicologicamente e causam um impacto em sua rotina, de modo que ele passa a dispor de um tempo reduzido para seus afazeres habituais, para o autocuidado e para se dedicar ao trabalho e ao lazer ${ }^{28}$.

Quando somente um familiar cuida do indivíduo em sofrimento psíquico, isso ocorre de maneira imperiosa devido à falta de alternativas e de pessoas disponíveis para dividir e administrar as demandas do ente. Essa resistência parte de uma realidade discriminatória e excludente, que sinaliza a debilidade das relações familiares. Assim, o ente em sofrimento psíquico não pode ser visto de maneira desintegrada do sistema familiar $^{29}$ :

Ninguém me entende, ninguém entende meu filho! Quando mais precisei, minha própria família não me ajudou! (F5).

Algumas vezes o ambiente familiar passa a ser campo de discórdias, de revolta e de inúmeros desacordos, e como a família não encontra saída para esses conflitos, acaba se dissolvendo. Assim, considerando o grau de dependência e a necessidade de atenção do indivíduo, cabe, inevitavelmente, ao familiar cuidador a responsabilidade de assumir o cuidado ${ }^{30}$.

Outro sentimento apontado nas rodas de TCI foi o de decepção e desgosto causados pelo desamparo familiar. Muitos familiares demonstraram que sua capacidade de cuidar foi reduzida por acompanharem o descaso e a negligência por parte dos outros entes no que diz respeito às demandas com a pessoa em sofrimento psíquico:

Às vezes, eu tenho tanto desgosto da vida, porque eu não carrego uma cruz de madeira, carrego uma de cimento. Pesada demais! (F2).

Me decepcionei com meu próprio sogro, porque, além de não me ajudar com o filho, ainda dizia que a culpa por ele ter adoecido era minha (F1).

Em estudo semelhante a este ${ }^{31}$, identificou-se que $13 \%$ dos familiares de pessoas em sofrimento psíquico, referiram sentimento de frustração, o que constitui uma variação do desgosto e da incapacidade que os assolava devido à dificuldade de lidar com os fatos e por não conseguirem transformar o status quo encontrado. Por conseguinte, a maneira como cada familiar se compor- ta na realidade do sofrimento mental pode variar e ser uma resposta para o que cada ser humano descobriu e aprendeu ao longo de sua vida ${ }^{32}$.

Além disso, muitos familiares sentiam-se sobrecarregados por não terem com quem partilhar os cuidados. E, mergulhados em um processo de desgaste contínuo, renunciavam grande parte de suas vidas, abandonando papéis sociais em razão dos esforços destinados ao ente "adoecido":

Quando vejo meu filho do jeito que está, enlouqueço porque não posso deixar ele só, mas tenho que trabalhar. Não tenho quem me ajude (F7).

Para muitos familiares é delicado sustentar uma convivência harmoniosa com o indivíduo em sofrimento psíquico, sobretudo quando se trata de um transtorno mental severo e persistente, visto que as oscilações de comportamento são frequentes e inadvertidas. Esse contato implica sobrecargas objetivas para o familiar que se sente obrigado a abdicar do trabalho e de sua vida social. Embora exista uma tendência à aceitação e à renúncia, alguns familiares se apropriam do cuidado contentes e com responsabilidade ${ }^{33}$.

Nessa perspectiva, é indispensável implementar estratégias no campo da saúde mental que sejam reconhecidamente capazes de auxiliar os familiares a enfrentarem essa realidade, por meio de visitas domiciliares, grupos familiares, além de outros recursos e práticas comunitárias, de modo a qualificar a família para reorganizar suas vidas e gerenciar o sofrimento psíquico ${ }^{34}$. Nesse contexto, a TCI é uma tecnologia de cuidado que pode ser aplicada com esse público, para inovar a forma de encontrar estratégias para que possa conviver com os conflitos e o sofrimento.

\section{O diálogo da compreensão e o respeito à alteridade}

A TCI celebra o amparo e a igualdade, pois é um chamamento voltado para a imersão do sujeito como abrigo e mensageiro da solidariedade, em uma ação que o motiva a se doar, a dar e receber amor, a ouvir e ser ouvido de modo que, a partir da "alteridade proposta pela TCI, possa reconhecer o outro e perceber-se nele, olhar e escutar com empatia, tocar com compaixão, perdoar, ser perdoado, resgatar a identidade e o senso de pertença" ${ }^{35}$ (p.64).

Durante a TCI, no momento da escolha do tema, constroem-se "identidades sociais" que são confrontadas a partir de dois elementos necessários ao entendimento dos sentidos existentes nas falas dos participantes: a alteridade e o contexto social. A noção de alteridade refere-se à presença 
de outro que apresenta visões peculiares acerca do ser humano, que envolvem a si e ao mundo. Nesse processo, há outra pessoa formada por traços particulares e, ao se relacionar com ela, muda de posição, deixa um lugar central e se dirige a outro lugar que envolve o adentrar o ambiente desse outro sujeito, ou seja, ocorre o deslocamento natural do indivíduo. Aceitar a alteridade significa reconhecer esse outro e admitir que há um universo constituído por ele ${ }^{36}$.

A alteridade é um conceito fundamental da Antropologia, uma condição daquilo que é outro, diferente, que representa o lugar do "não eu", em que as razões são analisadas para expressar o outro como diferente, descobrir suas singularidades e agregar a concepção de uma humanidade diversificada ${ }^{37}$.

Sendo assim, na realidade de familiares que convivem com o sofrimento psíquico, apesar das dificuldades e da indiferença que vivenciam, encontravam na TCI o acolhimento e a sensibilidade necessários para o encontro e o cuidado com o Outro. Nessa perspectiva, concebe-se a TCI como uma prática que pressupõe uma fonte de suporte capaz de canalizar emoções e sofrimentos, no sentido de recrutar as dores para uma dimensão concreta e factível, passível de ser trabalhada em um processo de alteridade grupa ${ }^{38}$ :

Como é bom se ver no outro e ver a importância que o outro tem para minha vida. Somos diferentes e ao mesmo tempo, iguais (F10).

Cada pessoa na Terapia Comunitária me ajudou muito. Antes, quando meu filho dizia uma coisa, eu dizia duas ou três. Hoje converso e respeito, entendo ele do jeito que é (F2).

A formação e a compreensão de si envolvem o reconhecimento de outro, um "receber o outro na sua alteridade, na sua diferença". O egresso de si rumo ao outro, na preocupação com o outro a partir de uma responsabilidade direcionada ao outro. Essa tendência representaria uma maneira de promover saúde praticando uma forma de cuidar em que o sujeito não se preocupa apenas consigo, mas se disponibiliza ao encontro do outro $^{39,40}$.

$\mathrm{Na}$ TCI, o espírito de alteridade é resgatado e reforçado, visto que ocorre uma relação inter-humana baseada nas experiências cotidianas que são clarificadas em um movimento de construção de identidades que transcende aquele espaço. Assim, a conquista dessa alteridade se expande para o contexto familiar, como uma possibilidade de cuidado baseado no respeito, na inclusão e no reforço da cidadania do ente em sofrimento psíquico:
Vejo que melhorei depois da Terapia Comunitária. Aprendi a lidar com minha filha, a lidar com a família, a respeitar cada um com seu jeito de ser. Entendo o "todo" (F3).

Ao estruturar uma atmosfera de acolhida, por meio da alteridade e da recuperação de competências, a TCI convida seus participantes a construírem outros sentidos para suas vidas, dá respostas e suscita alternativas para o enfrentamento dos problemas, em um ambiente favorável à prática do diálogo ${ }^{41}$ :

Depois da Terapia Comunitária, reuni meus filhos e o pai para conversar, dialogar. Eles passaram a me dar mais apoio (F8).

Depois da Terapia Comunitária, passei a aceitar melhor a situação dele. Aceito e encaro a realidade, comecei a respeitar o compasso dele e mudou tudo! (F5).

O diálogo se estabelece na junção de horizontes. Assim, um "horizonte" é uma compreensão do mundo vivido que leva a pessoa a encontrar outros horizontes por meio da linguagem, em um processo que gera compromissos linguísticos. O objetivo desse encontro é fazer com que os sujeitos se percebam e se compreendam, considerando a existência dos envolvidos ao possibilitar a adoção de propósitos partilhados ${ }^{42}$. Projetando-se para este estudo, a alteridade que o diálogo promove, representa um recurso acessível com respeito às diferenças e às limitações encontradas no convívio com a realidade do sofrimento psíquico.

No campo da saúde, perceber o outro como continuidade é uma virtude que repercute em atitudes sucessivas de valorização, inclusão e respeito. Na TCI, como as pessoas conseguem transformar a visão que têm de si mesmas, do outro e do contexto em que estão inseridas, tornam-se capazes de praticar o potencial e as habilidades que as levam a alcançar a alteridade ${ }^{23,43}$.

Assim, os entraves que são considerados como inerentes à vida particular e pessoal da família passam a compor uma subjetividade partilhada com base na sensibilidade adquirida no encontro com o sofrimento de outrem. É a partir desse movimento que a alteridade é reconhecida e fortalece o respeito e a criação de um universo comum de partilha social e coletiva ${ }^{44}$ :

Ouvindo os outros familiares, passei a juntar todo mundo em casa e disse que do jeito que estava não dava para continuar. Eu precisava da ajuda de todos, consegui resolver no diálogo (F8).

A palavra e a abertura ao diálogo são elementos úteis na TCI, pois é com eles que se constrói uma atmosfera sistêmica, colaborativa e de 


\section{Mudanças nas relações que constituem a posição do sujeito no sistema familiar}

Considerando que o papel da família é carregado de sentidos que se constroem no convívio com o sofrimento psíquico, o despertar desses familiares para a necessidade de acolher e de dar atenção ao sujeito com transtorno mental é crucial para que possam visualizar suas potencialidades e competências. Nesse sentido, é indispensável que os familiares possam assumir a posição que lhes cabe no sistema familiar, para que as relações sejam estruturadas numa perspectiva de interações afetivas e sociais comprometidas com o ato de cuidar e com a construção de sistemas de convivência harmoniosos.

Para isso, a família deve ser estimulada a problematizar o olhar que destina ao ente "adoecido", pois os sofrimentos e as experiências vivenciadas devem ser ressignificados no meio familiar, com o empenho de todos. Portanto, o familiar cuidador carece de espaços onde possa lidar com esses diferentes domínios do cotidiano e que influenciem diretamente a aceitação de si e do outro nas relações de vulnerabilidades geradas a partir da coexistência com o transtorno mental.

Assim, a TCI é uma prática que pode contribuir e produzir resultados positivos ao possibilitar um movimento de reflexão que conduz ao discernimento, à construção e ao fortalecimento de vínculos. Por se tratar de uma tecnologia capaz de potencializar a criação de vínculos, fomenta mudanças pessoais e coletivas que se estendem às comunidades e aos grupos sociais, em um processo de catarse e de pertencimento contínuos ${ }^{46}$ :

Quando ouvia as outras histórias na Terapia Comunitária, eu pensava nas minhas e pensava no meu comportamento, aquilo me dava uma direção (F9).

Hoje me sinto satisfeita e mesmo com as dificuldades, percebi que a gente nasceu para cuidar uns dos outros, para se ajudar (F1).

As falas dos participantes revelam satisfação com a TCI na medida em que se sentem acolhidos por um grupo que valoriza suas histórias de vida e enaltece o poder resiliente de cada um. Ao se enxergar nas experiências dos outros e ouvir os testemunhos de superação, passam a reconhecer suas capacidades de enfrentar as dificuldades relacionadas ao sofrimento psíquico:

Você muda muito com a Terapia Comunitária e acaba aprendendo muita coisa que faz parte do seu dia a dia, mas que não exercitava. Isso contribui porque você acaba tendo outra visão da vida (F10).

A Terapia Comunitária fez com que eu entendesse que cada caso é um caso e isso abriu minha mente para entender e mudar a realidade que vivo (F3).

$\mathrm{Na}$ TCI a existência de problemas e de objetivos comuns possibilita uma análise cautelosa da realidade experimentada no cuidado com o ente em sofrimento psíquico. Os participantes parecem encontrar nas falas dos demais as respostas necessárias para oxigenar uma esperança adormecida. Aquele movimento de partilha anuncia o ponto de partida para a mobilização, para o empoderamento e para a implicação efetiva de cada participante no sistema familiar.

Nesse processo, ele se reencontra e identifica atributos pessoais, juntamente com seu poder mobilizador que o remove de uma posição de permissividade e tonifica essa descoberta fazendo com que seja impulsionado a mudar. Desse modo, reconstrói-se e se encoraja para enfrentar as situações de risco ${ }^{47}$.

Gradativamente, o sujeito passa a enxergar o outro com novas lentes, independentemente de sua condição financeira, de seu status social, de etnia ou de gênero, respeita a diversidade e reconhece que cada um traz consigo uma riqueza cultural, de valores ou experiências de vida que podem ser úteis ao próximo, visto que ninguém sabe mais ou menos, mas tenta compreender bem mais a si mesmo. Os participantes passam a se espelhar nos outros, pois se veem neles, e isso gera laços de identificação e empatia que favorecem a inclusão e a adoção de uma nova consciência social ${ }^{48}$.

A Terapia Comunitária me ajudou a enxergar a vida. Às vezes, achava que o mundo ia acabar e que a família teria que seguir o mesmo caminho (F6).

$\mathrm{Na}$ Terapia Comunitária nós aprendemos um com o outro. Você aprende em um conjunto social com quem é doutor na maior instância do mundo e também com aquele que não sabe de nada do campo científico (F5).

Como a família é uma entidade que atua em conjunto e individualmente em seus constituintes, também é influenciada por seus membros, já que são pessoas que carregam particularidades e 
atributos próprios. Por se tratar de um complexo dinâmico e sistêmico, os indivíduos estão ciclicamente (re)assumindo papéis, e seu comportamento sofre interferências das funções e dos valores que assumem ${ }^{49}$.

Por conseguinte, as famílias precisam lançar mão de artifícios que estimulem a força que têm para ampliar o autocontrole e construir relações consolidadas no diálogo e na estima. Contudo, muitas vezes seus componentes não apresentam estratégias resolutivas para lidar com os conflitos, o que desencadeia aflições e sofrimento. Então, precisam de sujeitos engajados e comprometidos em restaurar e manter a instituição familiar com subsídios que instrumentem vinculações sociais por meio da amizade, do respeito, da espiritualidade, da comunicação efetiva, da participação em grupos comunitários de apoio, entre outros recursos que garantam esse suporte ${ }^{49}$.

Para isso, as pessoas devem "aprender a ser", para que possam (re)construir sua personalidade e aumentar a capacidade de agir com autonomia, sabedoria e responsabilidade social. Assim, é preciso refletir sobre a necessidade que as pessoas têm de exercitar o autocontrole e o autoconhecimento no contexto familiar, para que acreditem que o diálogo e o cuidado são fundamentais para a resolução de conflitos $^{50}$.

Entretanto, para que isso aconteça, na TCI, os familiares são incentivados a resgatar lembranças e qualidades latentes a partir da corrosão das relações desencadeada pela carga do sofrimento psíquico. Quando suas memórias são despertadas, as pessoas encontram em suas raízes o reforço de sua identidade e a força propulsora que estava reprimida e são conduzidas a um novo entendimento acerca do transtorno mental:

$\mathrm{Na}$ Terapia Comunitária, quando contavam uma experiência, isso me fazia refletir e me levava a mudar de planos sem saber (F5).

A Terapia Comunitária me ajudou no sentido de entender melhor a minha filha. Eu pensava até que tinha tantos problemas, mas pude ver que ela é uma bênção! (F3).

$\mathrm{Na} \mathrm{TCI}$, a pessoa se enxerga, reconstrói sua identidade e retorna a si e ao que sempre foi, o que representa um avanço para alguém que se perde em meio aos desafios $\operatorname{cotidianos}^{43}$. À medida que esses familiares se empoderavam e fortaleciam a autoconfiança, conscientizavam-se de que deveriam se emancipar e colocavam em prática o aprendizado adquirido nas rodas de TCI, mediando, com consciência, o ato de cuidar, em que a intencionalidade das ações os auxilia a adotar atitudes inclusivas e participativas:
Como depois da Terapia Comunitária comecei a me sentir melhor, mais tranquila, passei a confiar mais nele (F2).

$\mathrm{Na}$ TCI, as situações são compreendidas de modo sistêmico, agregando todos os fatos que compõem determinada realidade, o que faz com que seus participantes repensem a trama diária da vida. Assim, são levados a analisar cada circunstância, com um enfoque que é seu, mas também é do outro. Nesse movimento, eles se enxergam como partícipes do próprio contexto e devem desvelar os sentidos e as relações que ali existem, que podem ser de afetividade, hostilidade ou sofrimento ${ }^{48}$.

Ao participarem da TCI, os familiares encontraram oportunidades para repensar sua relação com o ente em sofrimento psíquico. No entanto, essa compreensão só é possível com a certeza de mudança e o crescimento pessoal:

Agora faço a minha parte, mas de outra maneira. Aqui me sinto acolhida e cuidada. A Terapia Comunitária me fez enxergar muitas verdades (F8).

Depois da Terapia Comunitária, deixei de ter medo de muita coisa. Hoje já deixo meu filho sair, ele vê que confio e quero que ele tenha coragem (F9).

Essas transformações se coadunam com a ideia de "inacabamento do ser humano", proposta por Paulo Freire e realçada na TCI por Adalberto Barreto, que está diretamente relacionada à consciência que o sujeito tem de ser alguém que não atingiu sua completude, mas que se modifica diariamente para tentar acertar. Essa apropriação se dá por meio da comunicação, da linguagem, das crenças e dos valores que se estabelecem de maneira profunda e que garantem ao ser humano a potencialidade para discernir, transpor obstáculos, analisar e refletir acerca de padrões sociais $^{23,44,51}$.

As falas dos familiares fazem referência às mudanças experimentadas depois de (re)conquistarem um novo papel social motivado pelo suporte oferecido na TCI, além do sentimento de pertença advindo do grupo. Assim, o familiar cuidador sente a necessidade de se inserir no processo terapêutico e de também ser cuidado em um ambiente onde possa ser compreendido juntamente com os nós que lhe afligem. E como a TCI é um espaço onde as histórias de um ecoam na vida do outro, os familiares se sentem aceitos e apoiados.

$\mathrm{Na}$ TCI, ao conhecer as maneiras como outros participantes conseguiram destinar resolutividade aos desafios, as pessoas começaram a 
refletir sobre si mesmas e sobre o mundo, expandiram os horizontes de compreensão, orientaram ativamente sua consciência para questões que consideravam desmerecidas de atenção e passaram a pô-las em evidência em um movimento de ressignificação e empoderamento.

Nesse ínterim, o evidenciado torna-se significativo, e o indivíduo o transfere para um cerne de mudança particular, encorajado por um processo de interação gerado no campo coletivo e passa a contar com um suporte instrutivo para a vida, em que as pessoas renovam e desenvolvem qualidades para viver em comunidade, dentro dos diversos subsistemas dos quais fazem parte, e não, apenas, na roda de $\mathrm{TCI}^{18,52}$.

\section{Considerações finais}

Ao analisar a potência da TCI na perspectiva do público investigado, elucidou-se sua eficácia como uma prática que facilitou mudanças nas esferas pessoal, familiar e comunitária dos participantes, visto que os resultados apontaram para interações sociais e individuais que estimularam os familiares a repensarem conceitos e a criarem espaços de convivência e de cuidado humanos e respeitosos que se difundiram sistemicamente.

Os familiares participantes reconheceram seu papel de corresponsabilização para melhorar e transformar o sistema familiar, propagando iniciativas de mudança que envolviam todos os membros da família e reforçavam a ideia de interação sistêmica. Acrescenta-se que, ao se mostrar como uma prática voltada para trabalhar os entraves enfrentados por familiares na vivência com o sofrimento psíquico, a TCI delineou um espaço de intercâmbio social que estimulou a reconstrução de valores e contribuiu para que seus participantes se ressignificassem e se determinassem a mudar.

Ao contribuir para suscitar diferentes formas de lidar com situações cotidianas, a TCI levou ainda os familiares a confiarem em si e na vida, a abandonar um convívio estereotipado e fatigante e a ocupar papéis facilitadores de aproximações e contatos capazes de estreitar as relações entre o familiar, o ente em sofrimento psíquico, a equipe multiprofissional e a comunidade.

\section{Colaboradores}

MAP Carvalho participou da concepção, do delineamento, da análise e interpretação dos dados, além da redação do artigo, sua revisão crítica e aprovação da versão a ser publicada. MD Dias participou da análise e interpretação dos dados, além da redação do artigo. SA Almeida participou da análise e interpretação dos dados, além da redação do artigo. RLR Ribeiro participou da análise e interpretação dos dados, além da redação do artigo. PMC Silva participou da análise e interpretação dos dados, além da redação do artigo. MO Ferreira Filha participou da concepção, do delineamento, da análise e interpretação dos dados, além da redação do artigo, sua revisão crítica e aprovação da versão a ser publicada. 


\section{Referências}

1. Aun JG, Vasconcellos MJE, Coelho SV. Atendimento de famílias e redes sociais: fundamentos teóricos e epistemológicos. Belo Horizonte: Ophicina da Arte \& Prosa; 2005.

2. Kuhn TS. A estrutura das revoluções científicas. São Paulo: Editora Perspectivas S.A; 1998 [1962].

3. Lyotard JF. A condição pós-moderna. $9^{\mathrm{a}}$ ed. Ed. Rio de Janeiro: José Olympio; 2006.

4. Lampert E. Pós-modernidade e conhecimento: educação, sociedade, ambiente e comportamento humano. Porto Alegre: Sulin; 2005.

5. Vasconcellos MJ. Pensamento sistêmico: o novo paradigma da Ciência. Campinas: Papirus; 2014.

6. Santos JL, Macedo RMS. Valores familiares e educação dos filhos na contemporaneidade. In: Macedo RMS. Terapia familiar no Brasil na última década. São Paulo: ROCA; 2008.

7. Tristiana RD, Yusuf A, Fitryasari R, Wahyuni SD, Nihayati HE. Perceived barriers on mental health services by the family of patients with mental illness. Int J Nurs Sci 2018; 5(1):63-67.

8. Wankiiri M, Drake KB, Meyer KR. The lived experience of families with a mentally ill family member. J Res Nurs Midwifery 2013; 3(4):58-66.

9. Hansson L, Jormfeldt H, Svedberg P, Svensson B. Mental health professionals' attitudes towards people with mental illness: do they differ from attitudes held by people with mental illness? Int J Soc Psychiatr 2013; 59(1):48-54.

10. Lancetti A. Clínica grupal com psicóticos: a grupalidade que os especialistas não entendem. In: Lancentti A. Saúde e loucura: grupos e coletivos. São Paulo: $\mathrm{Hu}-$ citec; 1993.

11. Santin G, Klafke TE. A família e o cuidado em saúde mental. Barbarói 2011; 34:146-160.

12. Abratecom. A Abratecom [Internet]. 2015 [acessado 2017 out 18]. Disponível em: http://www.abratecom. org.br/QuemSomos/Abratecom/.

13. Buzeli CP, Costa ALRC, Ribeiro RLR. Relatório Final da IV Conferência Nacional de Saúde Mental - Intersetorial. Brasília: CNS/MS; 2010.

14. Brasil. Ministério da Saúde (MS). Portaria no 145, de 11 de janeiro 2017. Altera procedimentos na Tabela de Procedimentos, Medicamentos, Órteses, Próteses e Materiais Especiais do SUS para atendimento na Atenção Básica. Diário Oficial da União 2017; 13 jan.

15. Andrade FB, Ferreira Filha MO, Dias MD, Silva AO, Costa ICC, Lima EAR, Mendes CKTT. Promoção da saúde mental do idoso na atenção básica: as contribuições da Terapia Comunitária. Texto Contexto Enferm 2010; 19(1):129-136.

16. Sá ANP, Rocha IA, Moraes MN, Braga LAV, Ferreira Filha MO, Dias MD. Conflitos familiares abordados na Terapia Comunitária integrativa. Rev Eletr Enferm 2012; 14(4):786-793.

17. Guerra CS, Dias MD, Ferreira Filha MO, Andrade FB, Reichert APS, Araújo VS. Do sonho à realidade: vivência de mães de filhos com deficiência. Texto Contexto Enferm 2015; 24(2):459-466.
18. Moraes MN. Terapia Comunitária Integrativa no sertão paraibano: avanços e desafios no contexto do SUS [dissertação]. João Pessoa: Universidade Federal da Paraíba; 2014.

19. Carvalho MAP, Dias MD, Miranda FAN, Ferreira Filha MO. Contribuições da Terapia Comunitária Integrativa para usuários dos Centros de Atenção Psicossocial (CAPS): do isolamento à sociabilidade libertadora. Cad Saude Publica 2013; 29(10):2028-2038.

20. Grittem L, Meier MJ, Zagonel IPS. Pesquisa-ação: uma alternativa metodológica para pesquisa em Enfermagem. Texto Contexto Enferm 2008; 17(4):765-770.

21. Monteiro CFS, Moreira MRC, Oliveira EAR, Moura MES, Costa JV. Pesquisa-ação: contribuição para prática investigativa do enfermeiro. Rev Gaucha Enferm 2010; 31(1):167-174.

22. Hochman B, Nahas FX, Oliveira Filho RS, Ferreira LN. Desenhos de pesquisa. Acta Cir Bras 2005; 20(Supl. 2):1-8.

23. Mendes R, Pezzato LM, Sacardo DP. Pesquisa-intervenção em promoção da saúde: desafios metodológicos de pesquisar "com". Cien Saude Colet 2016; 21(6):1737-1746.

24. Barreto AP. Terapia Comunitária passo a passo. Fortaleza: LCR; 2008.

25. Bardin L. Análise de conteúdo. São Paulo: Edições 70; 2011.

26. Brasil. Ministério da Saúde (MS). Conselho Nacional de Saúde (CNS). Resolução no 466, de 12 de dezembro de 2012. Diário Oficial da União 2013; $13 \mathrm{dez}$.

27. Dias AB, Silva MRS. Processos familiares no contexto do transtorno mental: um estudo sobre as forças da família. Cien Cuid Saude 2010; 9(4):791-798.

28. Delgado PG. Sobrecarga do cuidado, solidariedade e estratégia de lida na experiência de familiares de Centros de Atenção Psicossocial. Physis 2014; 24(4):11031126.

29. Kebbe LM, Rose LBR, Fiorati RC, Carreta LYD. Cuidando do familiar com transtorno mental: desafios percebidos pelos cuidadores sobre as tarefas de cuidar. Saude Debate 2014; 38(102):494-505.

30. Pimenta ES. A relação das famílias no tratamento do portador de transtorno mental realizado no Centro de Atenção Psicossocial: uma perspectiva institucionalista. Pesqui Prat Psicossoc 2008; 3(1):75-84.

31. Barroso AGC, Abreu LM, Bezerra MAA, Ibiapina SLD, Brito HB. Transtornos mentais: o significado para os familiares. RBPS 2004; 17(3):99-108.

32. Lino MA. A convivência de pessoas com transtornos mentais e seus familiares no contexto do domicílio [dissertação]. São Paulo: Universidade de São Paulo; 2006.

33. Santos DCS, Bandeira M. Estratégias de enfrentamentos e sobrecarga dos familiares cuidadores de pacientes psiquiátricos: revisão de literatura. Psicol Pesqui 2015; 9(1):88-104.

34. Barroso SM, Bandeira M, Nascimento E. Sobrecarga de familiares de pacientes psiquiátricos atendidos na rede pública. Rev Psiquiatr Clin 2007; 34(6):270-277. 
35. Pestana LSTC. A terapêutica integral de Jesus: análise exegética, hermenêutica, fenomenológica e antropológica dos milagres de Jesus nos textos neotestamentários e interfaces com a Terapia Comunitária integrativa [dissertação]. João Pessoa: Universidade Federal da Paraíba; 2017.

36. Fernandes MTO, Aquino EL, Santos GC, Soares SM, Lima LC. Terapia Comunitária: uma metodologia inovadora na Atenção Primária em Saúde no Brasil. Evidentia 2011; 8:34.

37. Santos WJ, Giacomin KC, Firmo JO. A. Alteridade da dor nas práticas de saúde coletiva: implicações para a atenção à saúde de pessoas idosas. Cien Saude Colet 2011; 20(12):3713-3721.

38. Camarotti MH. A doença como fonte de transformação: um estímulo à resiliência comunitária. In: Grandesso M, Barreto M, organizadores. Terapia Comunitária: tecendo redes para a transformação social, saúde, educação e políticas públicas. São Paulo: Casa do Psicólogo; 2007.

39. Levinás E. Totalidade e infinito. Lisboa: Biblioteca de Filosofa Contemporânea, Edições 70; 1980.

40. Bernardes AG, Quinhones DG. Práticas de cuidado e produção de saúde: formas de governamentalidade e alteridade. PSICO 2009; 40(2):153-161.

41. Grandesso M, Barreto M. Terapia Comunitária: tecendo redes para transformação social, saúde, educação e políticas públicas. São Paulo: Casa do Psicólogo; 2007.

42. Gadamer HG. Verdade e método II. Complementos e indice. 2a ed. Petrópolis: Vozes; 2004.

43. Martins PH. Dom do reconhecimento e saúde: elementos para entender o cuidado como mediação. In: Pinheiro R, Martins PH, organizadores. Usuários, redes sociais, mediações e integralidade em saúde. Rio de Janeiro: UERJ/IMS/LAPPIS; 2011.

44. Giffoni FAO, Santos MA. Terapia Comunitária como recurso de abordagem do problema do abuso do álcool na atenção primária. Rev Lat-Am Enferm 2011; 19(n. esp.):821-830.

45. Silva SSLL. Promoção da saúde e Terapia Comunitária: um diálogo que promove a participação social [monografia]. Brasília: Universidade de Brasília; 2009.

46. Ferreira Filha MA, Lazarte R, Barreto AP. Impacto e tendências do uso da Terapia Comunitária Integrativa na produção de cuidados em saúde mental. Rev Eletr Enf 2015; 17(2):172-177.

47. Ferreira Filha MO, Sá ANP, Rocha IA, Silva VLC, Souto CMRM, Dias MD. Alcoolismo no contexto familiar: estratégias de enfrentamento das idosas usuárias da Terapia Comunitária. Rev Rene 2012; 13(1):26-35.

48. Lazarte R. Sociología y Terapia Comunitaria Integrativa. Rev Uruguaya Enferm 2012; 7(1):67-76.

49. Nunes ECDA, Silva LWS. A subjetividade de enfermeiros expressando em arte o significado do cuidado à família. Texto Contexto Enferm 2011; 20(3):453-460.

50. Martins JJ, Barra DCC, Santos TM, Hinkel V, Nascimento ERP, Albuquerque GL, Erdmann AL. Educação em saúde como suporte para a qualidade de vida de grupos da terceira idade. Rev Eletr Enferm 2007; 9(2):443-456.
51. Freire P. Conscientização: teoria e prática da libertação: uma introdução ao pensamento de Paulo Freire. São Paulo: Centauro; 2001.

52. Grandesso M. Oi, gente... Eu não roubei galinhas! Contribuições do enfoque narrativo à Terapia Comunitária. In: Fukui L, Marchetti LB. A Terapia Comunitária no Brasil. Brasília: Anais do II Congresso Brasileiro de Terapia Comunitária; 2004.
Artigo apresentado em 23/05/2020 Aprovado em 22/10/2020

Versão final apresentada em 24/10/2020

Editores-chefes: Romeu Gomes, Antônio Augusto Moura da Silva 
